\title{
Perspectivas da alfabetização e letramento científico no Brasil: levantamento bibliométrico e opinião de profissionais da educação do ensino fundamental I
}

Perspectives of alphabetisation and scientific literacy in Brazil: bibliometric research and opinion from professional of education in the elementary school I

\author{
V. Gomes ${ }^{1} ;$ A. C. Santos ${ }^{1 *}$ \\ ${ }^{1}$ Faculdade de Medicina Veterinária e Zootecnia. Universidade de São Paulo. CEP 05508-270. São Paulo, SP, \\ Brasil \\ *amiltonsantoss@usp.br
}

(Recebido em 02 de fevereiro de 2018; aceito em 16 de maio de 2018)

\begin{abstract}
Alfabetização científica (AC) constitui a capacidade de compreender, utilizar e refletir sobre um tema, utilizando a linguagem científica. Letramento científico (LC) se relaciona com a função e prática social utilizando o conhecimento científico. Estes temas têm ganhado relevância devido aos avanços científicos e tecnológicos da sociedade atual. $\mathrm{O}$ objetivo deste trabalho foi realizar um levantamento bibliométrico buscando pesquisadores brasileiros, os quais se dedicam aos estudos sobre AC/LC no Ensino Fundamental I (EFI). E, em seguida, realizar um levantamento da percepção de profissionais da educação sobre temas envolvendo AC/LC e metodologias e ferramentas envolvidas no ensino das Ciências Naturais no EFI. O levantamento bibliométrico foi realizado na plataforma Scielo.br. A percepção dos profissionais da educação (diretoras, coordenadoras pedagógicas e docentes) sobre AC/LC no EFI foi levantada por meio de questionários de múltipla escolha. Através do levantamento bibliométrico foram identificados 23 artigos (seis com foco no EFI) utilizando as palavras chave alfabetização científica. Utilizando as palavras alfabetização científica e letramento identificou-se oito artigos e como as palavras letramento científico identificou-se quatro artigos, sendo que, nas duas buscas não foram identificados artigos com foco no EFI. Resumidamente, a segunda parte da pesquisa revelou o apoio e reconhecimento sobre a necessidade de programas eficazes envolvendo AC/LC no EFI e a necessidade em se propor metodologias inovadoras de ensino em Ciências Naturais reforçada pela capacitação dos docentes. Nenhuma das escolas analisadas possuía laboratório e a maioria das docentes assumiu que, os cursos de graduação não capacitam os professores a atuar com metodologias experimentais no ensino de Ciências no EFI.

Palavras-chave: Conhecimento científico, Ensino de ciências, Metodologia de ensino de ciências.
\end{abstract}

Scientific Alphabetisation (SA) is the ability to understand, use and reflect on a topic, using scientific language. Scientific literacy (SL) is related to the function and social practice using scientific knowledge. These issues have gained relevance due to the scientific and technological advances of today's society. The aim of this work was to carry out a bibliometric survey looking for Brazilian researchers, who are dedicated to the studies on SA/SL in Elementary School I (EFI). And then perform a research on perception of educational professionals on topics involving SA/SL and methodologies and tools involved in teaching of Natural Sciences during EFI. The bibliometric survey was carried out on the Scielo.br platform. The perception of education professionals (directors, pedagogical coordinators and teachers) on SA/SL in EFI was raised through multiple choice questionnaires. Through the bibliometric survey, 23 articles (six focusing on EFI) were identified using the key words scientific literacy. Using the words scientific alphabetisation and literacy, eight articles were identified and using the words scientific literacy four articles was identified. In the two latest searches no articles focused on EFI were identified. Briefly, the second part of the research revealed the support and recognition of the need for effective programs involving SA/SL in EFI and the need to propose innovative teaching methods in Natural Sciences reinforced by teacher training. None of the schools analyzed had a laboratory and most teachers assumed that undergraduate courses do not enable teachers to work with experimental methodologies in Natural Science teaching at EFI.

Keywords: Methodology of teaching science, Scientific knowledge, Teaching science. 


\section{INTRODUÇÃO}

O ensino de ciências tem ganhado relevância na medida em que vivemos em um mundo globalizado e que adentramos a quarta revolução industrial ou revolução 4.0. A quarta revolução industrial não é definida por um conjunto de tecnologias emergentes em si mesmas, mas a transição em direção a novos sistemas que foram construídos sobre a infraestrutura da revolução digital. Estes sistemas se baseiam na convergência tecnológica nas áreas física, biológica e digital [1]. Esse processo exige dos indivíduos melhores habilidades para lidar com um universo de conhecimento científico e tecnológico no qual estão expostos diariamente. Ao mesmo tempo, exige-se das sociedades, investimento estratégico e dirigido, na área da informação, ciência e tecnologia, visando fomentar as inovações científico-tecnológicas, requeridas para tornar o país competitivo no cenário internacional [2]. Diante deste contexto, Morais e Paiva (2014) [3] destacam que, é crucial que a educação em ciência, e consequentemente o ensino das ciências, contribua para problematizar o saber e contextualizar os conhecimentos, de modo que os alunos possam apropriar-se deles e mobilizá-los convenientemente em diversas situações com as quais são confrontados no cotidiano. Sendo assim, é fundamental preparar os alunos para pensar criticamente em um mundo de contínuas e aceleradas transformações científicas e tecnológicas e motivá-los para se envolverem na aprendizagem das ciências, visando potencializar a busca ativa pelo conhecimento.

Diante deste contexto, durante o $2^{\circ}$ Seminário sobre Diplomacia e Inovação Científica e Tecnológica: Ação Internacional no Brasil, promovido pelo Ministério das Relações Exteriores [4], foram discutidas ações e políticas públicas com o objetivo de incentivar a inovação científicotecnológica no Brasil. Diante do exposto, pesquisadores têm discutido sobre a eficácia das metodologias para o ensino das Ciências $[5,6,7,8]$ e dos programas de alfabetização científica (AC) e letramento científico (LC) como parte deste processo.

Alfabetização é o processo de ensino da língua escrita [9], enquanto $\mathrm{AC}$ relaciona-se com a capacidade de compreender, utilizar e refletir sobre um tema, utilizando a linguagem científica, promovendo a participação ativa e adequada nas práticas sociais e profissionais $[6,10,11,12$, 13]. O termo letramento possui caráter de inserção e prática social através da língua escrita [9], enquanto o LC se relaciona com a função e prática social de um indivíduo utilizando o conhecimento científico $[5,10,11,13]$.

A celeridade com que as inovações científico-tecnológicas ocorrem, exige eficazes e eficientes programas de AC/LC das sociedades. Porém, um alerta sobre a eficácia do ensino de Ciências no Brasil fica evidente quando se revelam os resultados dos Indicadores de Letramento Científico (ILC) da sociedade acima de 15 anos de idade, os quais demonstraram que, apenas $5 \%$ da população podem ser consideradas letradas cientificamente. Outro alerta foram os resultados do Programme International for Student Assessment (PISA) [13], os quais demonstraram que, em 2016, os alunos brasileiros de até 15 anos de idade estavam na $63^{\circ}$ posição em conhecimento em Ciências entre as 70 nações avaliadas. Além desses dois indicadores, o Centro de Gestão e Estudos Estratégicos (CGEE) e o Ministério da Ciência, Tecnologia e Inovação (MCTI), revelaram em uma pesquisa que, os brasileiros possuem algum interesse sobre assuntos de ciência e tecnologia, mas continuam com acesso escasso à informação científica e tecnológica, especialmente quando analisados indivíduos das camadas sociais de menor escolaridade e renda [14]. Com os mesmos resultados considerados desfavoráveis ao desenvolvimento científico e tecnológico do Brasil, uma pesquisa da agência Datafolha encomendada pela Agência FAPESP, revelou que, 79\% dos entrevistados não acessam conteúdo sobre ciência por considerarem assuntos complicados e não conseguirem entendê-los. A pesquisa demonstrou que, um quarto dos entrevistados respondeu que a escola foi a responsável pela perda do interesse pela ciência [15].

Como observado, os diversos setores da sociedade brasileira necessitam discutir a temática envolvendo a alfabetização e letramento científico da população. Estas discussões são essenciais para se buscar estratégias mais eficazes envolvendo o ensino-aprendizagem em Ciências Naturais e tecnologias. Neste contexto, é primordial a busca por estratégias envolvendo metodologias mais eficazes para o ensino de Ciências Naturais. Como ponto de partida, um levantamento dos autores que se dedicam às pesquisas sobre alfabetização e letramento científico permitiria entender em que tipo de pesquisas estes cientistas têm se dedicado nos últimos anos. Na mesma vertente, um 
diagnóstico da percepção dos docentes que atuam no ensino fundamental I sobre o ensino de Ciências Naturais poderia auxiliar na compreensão dos diversos fatores envolvidos na problemática do baixo conhecimento científico da população brasileira, demonstrado nas avaliações descritas anteriormente. Assim, o objetivo deste trabalho foi realizar um levantamento bibliométrico buscando pesquisadores brasileiros, os quais se dedicam aos estudos sobre AC/LC no Ensino Fundamental I (EFI). E, em seguida, realizar uma pesquisa por meio de questionários, buscando entender a opinião de profissionais da educação que atuam no EFI sobre novas metodologias e ferramentas envolvidas no ensino das Ciências Naturais.

\section{METODOLOGIA}

\subsection{Parte 1: pesquisa bibliométrica sobre alfabetização e letramento científico em periódicos nacionais}

O primeiro passo do trabalho foi a realização de uma pesquisa bibliométrica de artigos científicos, na plataforma Scielo.br, a qual possui periódicos nacionais com foco no tema deste trabalho, os quais são editados por muitos dos principais especialistas da área da Educação no país. A pesquisa bibliométrica pode ser quantitativa, qualitativa, ou mesclando os dois tipos, como abordado no presente estudo. A pesquisa bibliométrica se utiliza da busca por palavras-chave. Para tanto, foram utilizadas inicialmente, as palavras-chaves: alfabetização científica, depois alfabetização científica e letramento e por último, letramento científico. Após a busca, os artigos foram quantificados numericamente e qualificados de acordo com o foco (se tratavam o assunto no EFI ou não), o ano das publicações; e, a distribuição geográfica das universidades-sede dos pesquisadores. Os resultados foram agrupados em tabelas e gráficos, buscando evidenciar o período em que houve maior número de publicações relacionadas com o tema em questão e aqueles que tratavam o assunto no EFI.

\subsection{Parte 2: opinião dos profissionais da educação no EFI sobre temas envolvendo AC/LC e metodologias de ensino de ciências naturais}

No segundo momento, foi aplicado um questionário com temas relacionados à $\mathrm{AC} / \mathrm{LC}$ e ao ensino de Ciências. O questionário foi montado buscando evidenciar os temas amplamente discutidos nos artigos científicos encontrados no levantamento bibliométrico. A entrevista foi realizada com diretores de escolas $(n=8)$ (questionário 1$)$, coordenadores pedagógicos $(n=9)$ (questionário 2) e professores, distribuídos entre o primeiro e quinto ano $(\mathrm{n}=42)$ (questionário 3). Todos os profissionais atuavam no EFI da rede pública municipal da cidade de São João da Boa Vista, no interior do estado de São Paulo, Brasil, com uma população de aproximadamente 100.000 habitantes. Os questionários traziam 10 questões fechadas, de múltipla escolha, com as opções "sim" ou "não". Algumas questões eram iguais para as diferentes entrevistadas (diretoras, coordenadoras pedagógicas e docentes), porém algumas questões eram diferentes por se tratar de temas pertinentes apenas se respeitadas as diferentes funções hierárquicas de cada entrevistado (diretoras, coordenadoras pedagógicas e docentes). Após a aplicação dos questionários, as respostas foram agrupadas em tabelas, evidenciando o percentual de respostas (sim/não) para cada uma das questões. Para sua realização, esta pesquisa contou com a autorização dos diretores das escolas. Os participantes da entrevista assinaram os Termos de Consentimento Livre e Esclarecido (TCLE). O projeto de pesquisa foi submetido e aprovado pelo Comitê de Ética da Faculdade de Medicina Veterinária e Zootecnia da Universidade de São Paulo (Processo: CEUAx 6801140817). O projeto também foi submetido e aprovado pela Plataforma Brasil, por se tratar de uma pesquisa envolvendo seres humanos (Parecer 2.435.122). 


\section{RESULTADOS}

\subsection{Pesquisa bibliométrica: artigos utilizando as palavras-chave: alfabetização científica}

Foram encontrados 23 artigos (Tabela 1), distribuídos em cinco revistas: 7 na Ensaio Pesquisa em Educação em Ciências, 1 na Educação \& Realidade, 3 na Revista Brasileira de Educação, 11 na Ciência \& Educação e 1 na Ambiente \& Educação. Um dos artigos científicos se tratava de uma produção de autores mexicanos e espanhóis [16] e outro de portugueses e espanhóis [17] com foco em seus países. Pode-se constatar que, dos 23 artigos investigados, somente 6 (26\%) trabalhos $[5,7,18,19,20,21]$ estavam relacionados à AC/LC no EFI brasileiro.

Tabela 1: Listas em ordem cronológica de artigos encontrados com as palavras chaves: Alfabetização Cientifica até o ano de 2017 na plataforma scielo.br.

\begin{tabular}{|c|c|c|c|}
\hline Título do Artigo & $\begin{array}{l}\text { Autores/ano da } \\
\text { publicação }\end{array}$ & $\begin{array}{l}\text { Universidade } \\
\text { (estado) }\end{array}$ & Revistas (ISSN) \\
\hline $\begin{array}{l}\text { Alfabetização científica no contexto das séries } \\
\text { iniciais }\end{array}$ & $\begin{array}{l}\text { LORENZETTI; } \\
\text { DELIZOICOV } \\
(2001)[5]\end{array}$ & $\begin{array}{l}\text { Universidade do } \\
\text { Contestado (SC) } \\
\text { Universidade Federal } \\
\text { de Santa Catarina } \\
\text { (SC) }\end{array}$ & $\begin{array}{l}\text { Ensaio Pesquisa } \\
\text { em Educação em } \\
\text { Ciências (ISSN } \\
\text { 1983-2117) }\end{array}$ \\
\hline $\begin{array}{l}\text { A alfabetização científica e o processo de ler e } \\
\text { escrever em séries iniciais: emergências de um } \\
\text { estudo de investigação-ação. }\end{array}$ & $\begin{array}{l}\text { BRANDI; GURGEL } \\
\text { (2002) }[18]\end{array}$ & $\begin{array}{l}\text { Universidade } \\
\text { Metodista de } \\
\text { Piracicaba (SP) }\end{array}$ & $\begin{array}{l}\text { Ciência \& } \\
\text { Educação (ISSN } \\
\text { 1980-850X) }\end{array}$ \\
\hline $\begin{array}{l}\text { O ensino de física das radiações na formação de } \\
\text { auxiliares de enfermagem e atendentes de } \\
\text { consultórios odontológicos: sondagem de } \\
\text { concepções sobre os raios-x com enfoque na } \\
\text { prevenção e tecnologia }\end{array}$ & $\begin{array}{l}\text { COSTA; COSTA } \\
(2002)[22]\end{array}$ & $\begin{array}{l}\text { Universidade Estadual } \\
\text { de Maringá (PR) }\end{array}$ & $\begin{array}{l}\text { Ciência \& } \\
\text { Educação (ISSN } \\
\text { 1980-850X) }\end{array}$ \\
\hline $\begin{array}{l}\text { Alfabetização científica: uma possibilidade para } \\
\text { a inclusão social }\end{array}$ & $\begin{array}{l}\text { CHASSOT (2003) } \\
{[23]}\end{array}$ & $\begin{array}{l}\text { Universidade Vale do } \\
\text { Rio dos Sinos (RS) }\end{array}$ & $\begin{array}{l}\text { Revista } \\
\text { Brasileira de } \\
\text { Educação (ISSN } \\
\text { 1809-449X) }\end{array}$ \\
\hline $\begin{array}{l}\text { O papel da natureza da ciência na educação para } \\
\text { a cidadania. }\end{array}$ & $\begin{array}{l}\text { PRAIA; GIL- } \\
\text { PÉREZ; VILCHES } \\
(2007)[16]\end{array}$ & $\begin{array}{l}\text { Universidade de } \\
\text { Aveiro; } \\
\text { Universitat de } \\
\text { Valéncia; } \\
\text { Instituto de Educación } \\
\text { Secundaria de } \\
\text { Valéncia }\end{array}$ & $\begin{array}{l}\text { Ciência \& } \\
\text { Educação (ISSN } \\
\text { 1980-850X) }\end{array}$ \\
\hline $\begin{array}{l}\text { Educação científica na perspectiva de letramento } \\
\text { como prática social: funções, princípios e } \\
\text { desafios }\end{array}$ & SANTOS (2007) [24] & $\begin{array}{l}\text { Universidade de } \\
\text { Brasília (DF) }\end{array}$ & $\begin{array}{l}\text { Revista } \\
\text { Brasileira de } \\
\text { Educação (ISSN } \\
\text { 1809-449X) }\end{array}$ \\
\hline $\begin{array}{l}\text { Alfabetização científica no clube de ciências do } \\
\text { ensino fundamental: uma questão de inscrição }\end{array}$ & $\begin{array}{l}\text { OLIVEIRA (2010) } \\
{[19]}\end{array}$ & $\begin{array}{l}\text { Universidade Estadual } \\
\text { de Londrina }(\mathrm{PR})\end{array}$ & $\begin{array}{l}\text { Ensaio Pesquisa } \\
\text { em Educação em } \\
\text { Ciências (ISSN } \\
\text { 1983-2117) }\end{array}$ \\
\hline $\begin{array}{l}\text { Ensino de ciências no fundamental 1: perfil de } \\
\text { um grupo de professores em formação } \\
\text { continuada num contexto de alfabetização } \\
\text { científica }\end{array}$ & $\begin{array}{l}\text { NIGRO; AZEVEDO } \\
(2011)[20]\end{array}$ & $\begin{array}{l}\text { Grupo de estudo e } \\
\text { pesquisa em ensino de } \\
\text { Ciências (SP) }\end{array}$ & $\begin{array}{l}\text { Ciência \& } \\
\text { Educação (ISSN } \\
1980-850 X)\end{array}$ \\
\hline $\begin{array}{l}\text { Construindo argumentação na sala de aula: a } \\
\text { presença do ciclo argumentativo, os indicadores } \\
\text { de alfabetização científica e o padrão de } \\
\text { Toulmin. }\end{array}$ & $\begin{array}{l}\text { SASSERON; } \\
\text { CARVALHO, (2011) } \\
{[25]}\end{array}$ & $\begin{array}{l}\text { Universidade de São } \\
\text { Paulo (SP) }\end{array}$ & $\begin{array}{l}\text { Ciência \& } \\
\text { Educação (ISSN } \\
\text { 1980-850X) }\end{array}$ \\
\hline
\end{tabular}




\begin{tabular}{|c|c|c|c|}
\hline $\begin{array}{l}\text { Oxigênio: uma abordagem filosófica visando } \\
\text { discussões acerca da educação em ciências - } \\
\text { parte 1: poder e ambição. }\end{array}$ & $\begin{array}{l}\text { MOREIRA (2012) } \\
{[26]}\end{array}$ & $\begin{array}{l}\text { Universidade Federal } \\
\text { do Rio de Janeiro (RJ) }\end{array}$ & $\begin{array}{l}\text { Ciência \& } \\
\text { Educação (ISSN } \\
\text { 1980-850X) }\end{array}$ \\
\hline $\begin{array}{l}\text { As interações discursivas no ensino de física: a } \\
\text { promoção da discussão pelo professor e a } \\
\text { alfabetização científica dos alunos. }\end{array}$ & $\begin{array}{l}\text { SOUZA; } \\
\text { SASSERON (2012) } \\
{[27]}\end{array}$ & $\begin{array}{l}\text { Universidade de São } \\
\text { Paulo (SP) }\end{array}$ & $\begin{array}{l}\text { Ciência \& } \\
\text { Educação (ISSN } \\
\text { 1980-850X) }\end{array}$ \\
\hline $\begin{array}{l}\text { Educação ambiental para a escola básica: } \\
\text { contribuições para o desenvolvimento da } \\
\text { cidadania e da sustentabilidade }\end{array}$ & $\begin{array}{l}\text { KONDRAT; } \\
\text { MACIEL (2013) [7] }\end{array}$ & $\begin{array}{l}\text { Instituto de Botânica } \\
\text { de São Paulo (SP); } \\
\text { Universidade } \\
\text { Cruzeiro do Sul (SP) }\end{array}$ & $\begin{array}{l}\text { Revista } \\
\text { Brasileira de } \\
\text { Educação (ISSN } \\
\text { 1809-449X) }\end{array}$ \\
\hline
\end{tabular}

A alfabetização científica na educação de jovens e adultos em atividades baseadas no programa

RAMOS; SÁ (2013) Universidade Estadual em Educação em "mão na massa" de Santa Cruz (BA) Ciências (ISSN 1983-2117)

O ensino informal de ciências no ambiente de postos de saúde: uma analogia com o ambiente museotécnico à luz da teoria sócio-histórica de Vygotski.

\begin{tabular}{llll}
$\begin{array}{l}\text { O ensino informal de ciências no ambiente de } \\
\text { postos de saúde: uma analogia com o ambiente } \\
\text { museotécnico à luz da teoria sócio-histórica de } \\
\text { Vygotski. }\end{array}$ & $\begin{array}{l}\text { RAZERA; SOUZA } \\
(2013)[29]\end{array}$ & $\begin{array}{l}\text { Universidade Estadual } \\
\text { do Sudoeste da Bahia } \\
\text { (BA) }\end{array}$ & $\begin{array}{l}\text { Ensaio Pesquisa } \\
\text { em Educação em } \\
\text { Ciências (ISSN } \\
1983-2117)\end{array}$ \\
\hline $\begin{array}{l}\text { Alfabetização científica: questões para reflexão. } \\
\text { TEIXEIRA (2013) } \\
{[30]}\end{array}$ & $\begin{array}{l}\text { Universidade Federal } \\
\text { de Pernambuco (PE) }\end{array}$ & $\begin{array}{l}\text { Ciência \& } \\
\text { Educação (ISSN } \\
1980-850 X)\end{array}$ \\
\hline $\begin{array}{l}\text { Ciência e ideologia na prática dos professores de } \\
\text { sociologia no ensino médio: da neutralidade } \\
\text { impossível ao engajamento indesejável, ou seria } \\
\text { o inverso? }\end{array}$ & MORAES (2014) & $\begin{array}{l}\text { Universidade de São } \\
\text { Paulo (SP) }\end{array}$ & $\begin{array}{l}\text { Educação \& } \\
\text { Realidade (ISSN } \\
2175-6236)\end{array}$ \\
\hline
\end{tabular}
o inverso?

Universidade Federal

Teatro de temática científica: conceituação, conflitos, papel pedagógico e contexto brasileiro. do Rio de Janeiro

(RJ);

Universidade de São Paulo (SP)
Ciência \&

Educação (ISSN

1980-850X)

Ensaio Pesquisa em Educação em Ciências (ISSN 1983-2117)

MOTOKANE (2015) Universidade de São [33] Paulo (SP)

\section{MARANDINO}

(2015) [32]
Sequências didáticas investigativas e argumentação no ensino de ecologia

El campo de la salud ambiental: una oportunidad
para alcanzar las metas de la educación científica

$\begin{array}{ll} & \text { Universidad } \\ & \text { Autónoma de } \\ \text { ROBLES; CHÁVEZ; } & \text { Barcelona; } \\ \text { BALLESTEROS } & \text { Universidad de } \\ \text { (2015) [17] } & \text { Guadalajara; } \\ & \text { Universidad } \\ & \text { Autónoma de Madrid }\end{array}$

Alfabetização científica, ensino por investigação e argumentação: relações entre ciências da natureza e escola. $\begin{array}{ll}\text { SASSERON (2015) } & \text { Universidade de São } \\ \text { [34] } & \text { Paulo (SP) }\end{array}$
Ambiente \& Sociedade (ISSN 1809-4422)

Ensaio Pesquisa em Educação em Ciências (ISSN 1983-2117)

Relações entre leitura, escrita e alfabetização/ letramento científico: um levantamento bibliográfico em periódicos nacionais da área de ensino de ciências

$\begin{array}{ll}\text { SUISSO; } & \begin{array}{l}\text { Universidade Federal } \\ \text { GALIETA (2015) } \\ \text { do Rio de Janeiro (RJ) }\end{array}\end{array}$

Ciência \& Educação (ISSN 1980-850X)

Ensino de ciências por investigação: uma estratégia pedagógica para promoção da alfabetização científica nos primeiros anos do ensino fundamental

$\begin{array}{ll}\text { BRITO; FIREMAN } & \begin{array}{l}\text { Universidade Federal } \\ \text { de Alagoas (AL) }\end{array}\end{array}$

Ensaio Pesquisa em Educação em Ciências (ISSN 1983-2117)
Regência e análise de uma sequência de aulas de ROSA; SUART; química: contribuições para a formação inicial docente reflexiva.
MARCONDES

(2017) [35]
Universidade Federal de Lavras (MG); Universidade de São Paulo (SP)
Ciência \&

Educação (ISSN 1980-850X) 
Pode-se constatar que, todos os artigos foram publicados a partir do ano de 2001. Porém não se exclui que possa haver artigos anteriores, pois se sabe que, muitos periódicos ainda não possuem seus acervos mais antigos disponíveis em sua versão digitalizada. $\mathrm{O}$ ano em que houve o maior número de publicações foi 2015 (5 artigos). Após 2014 (ano de publicação do ILC no país), foram encontrados 7 artigos. Desses artigos, 5 foram publicados no ano de 2015, sendo que, nenhum tratava do assunto no EFI. No ano de 2016 foi encontrado 1 artigo, o qual tratava do assunto no EFI. No ano de 2017 foi encontrado 1 artigo, o qual não tratava do assunto no EFI. A localização geográfica dos autores revelou que: a maioria dos autores que discutem o tema está concentrada em universidades do estado de São Paulo (11); seguidos do Rio de Janeiro (3); Paraná (2); Santa Catarina (2) e Bahia (2). Em Alagoas, Distrito Federal, Minas Gerais, Pernambuco e Rio Grande do Sul houve somente um registro para cada estado (Figura 1).

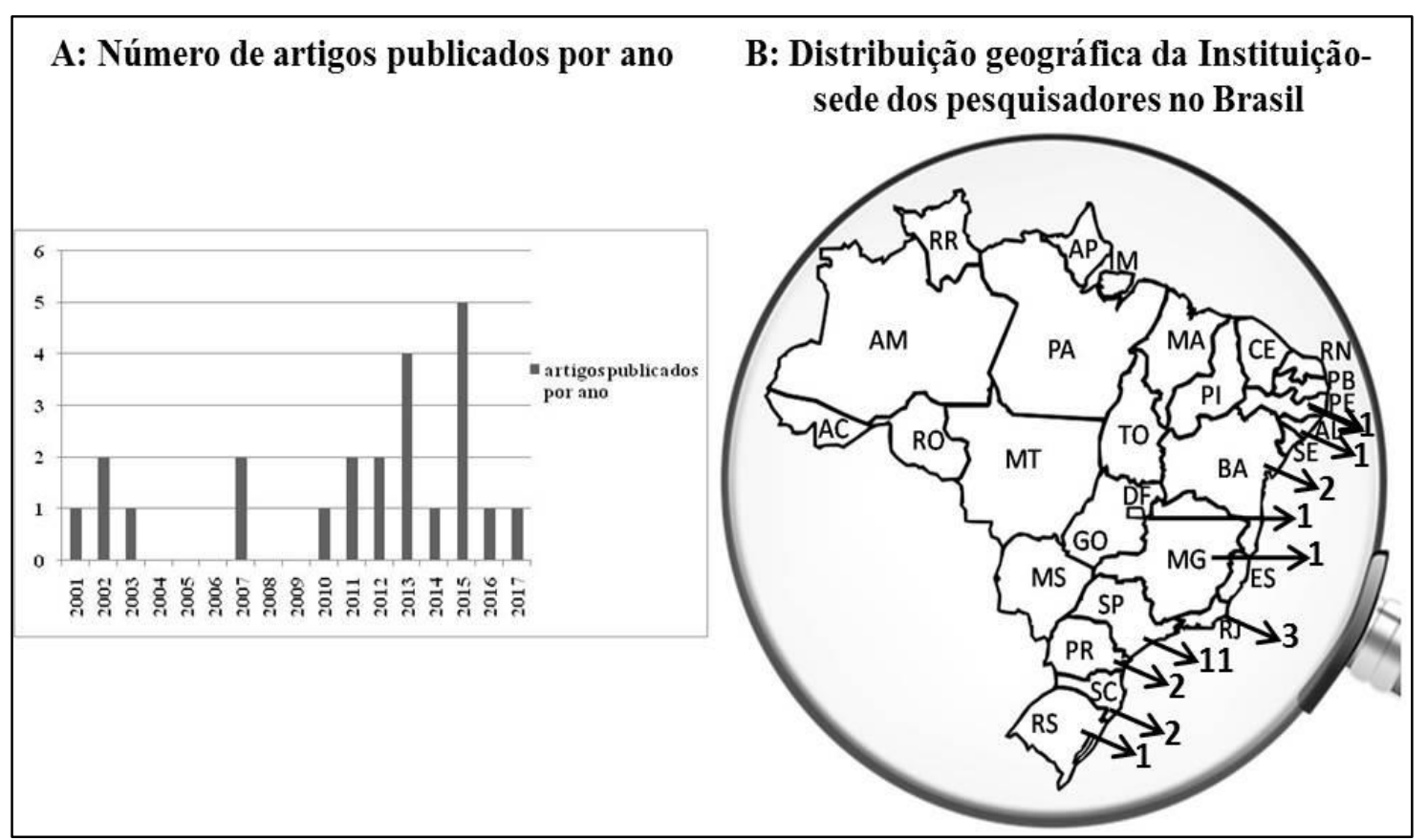

Figura 1: Gráfico demonstrativo da cronologia dos artigos e a distribuição geográfica da instituiçãosede dos pesquisadores encontrados na plataforma Scielo.br, utilizando as palavras-chave: alfabetização científica.

\subsection{Pesquisa bibliométrica: artigos utilizando as palavras-chave: alfabetização científica e letramento}

Foram encontrados 8 artigos (Tabela 2), distribuídos em seis revistas: 2 na Revista Brasileira de Educação, 2 na revista Ciência \& Educação, e 1 em cada uma das revistas a seguir: Educação e Pesquisa, Audiology, Communication Research, Cadernos Cedes e Revista Brasileira de Enfermagem. Como dito anteriormente, não se exclui que possa haver artigos anteriores, pois se sabe que, muitos periódicos ainda não possuem seus acervos mais antigos disponíveis em sua versão digitalizada. Três dos artigos $[11,24,30]$ foram encontrados anteriormente na busca pelas palavras-chave alfabetização científica. Entre os autores, todos apareceram em apenas um trabalho científico. Nenhum dos 8 trabalhos discutia o tema no EFI.

A localização geográfica dos autores revelou que: a maioria dos autores que discutem o tema está concentrada em universidades no estado de São Paulo (4). Com apenas o registro de um autor estão os estados: Rio de Janeiro, Distrito Federal, Minas Gerais, Pernambuco e Rio Grande do Sul. Todos os artigos foram publicados a partir do ano 2006. No entanto, o ano em que houve o maior número de publicações foi o ano de 2017 (3 artigos). Após 2014 (ano da publicação do ILC no Brasil), foram encontrados 4 artigos. Desses artigos, 1 foi publicado no ano de 2015 e 3 no ano de 2017, os quais não tratavam do assunto no EFI (Figura 2). 
Tabela 2: Listas em ordem cronológica de artigos encontrados com as palavras-chave: Letramento e Alfabetização Cientifica até o ano de 2017 na plataforma Scielo.br.

\begin{tabular}{|c|c|c|c|}
\hline Título do Artigo & $\begin{array}{l}\text { Autores/ano da } \\
\text { publicação }\end{array}$ & $\begin{array}{l}\text { Universidade } \\
\text { (estado) }\end{array}$ & Revistas (ISSN) \\
\hline $\begin{array}{l}\text { Leitura e alfabetização no Brasil: uma } \\
\text { busca para além da polarização. }\end{array}$ & $\begin{array}{l}\text { BELINTANE } \\
\text { (2006) [36] }\end{array}$ & $\begin{array}{l}\text { Universidade de } \\
\text { São Paulo (SP) }\end{array}$ & $\begin{array}{l}\text { Educação e Pesquisa } \\
\text { (ISSN 1678-4634) }\end{array}$ \\
\hline $\begin{array}{l}\text { Educação científica na perspectiva de } \\
\text { letramento como prática social: funções, } \\
\text { princípios e desafios. }\end{array}$ & SANTOS (2007) [24] & $\begin{array}{l}\text { Universidade de } \\
\text { Brasília (DF) }\end{array}$ & $\begin{array}{l}\text { Revista Brasileira de } \\
\text { Educação (ISSN } \\
\text { 1809-449X) }\end{array}$ \\
\hline $\begin{array}{l}\text { Alfabetização científica: questões para } \\
\text { reflexão. }\end{array}$ & $\begin{array}{l}\text { TEIXEIRA (2013) } \\
\text { [30] }\end{array}$ & $\begin{array}{l}\text { Universidade } \\
\text { Federal de } \\
\text { Pernambuco (PE) }\end{array}$ & $\begin{array}{l}\text { Ciência \& Educação } \\
\text { (ISSN 1980-850X) }\end{array}$ \\
\hline $\begin{array}{l}\text { Letramento e alfabetização de pessoas } \\
\text { jovens e adultas: um balanço da } \\
\text { produção científica }\end{array}$ & $\begin{array}{l}\text { VÓVIO; KLEIMAN } \\
\text { (2013) [37] }\end{array}$ & $\begin{array}{l}\text { Universidade } \\
\text { Federal de São } \\
\text { Paulo (SP) } \\
\text { Universidade } \\
\text { Estadual de } \\
\text { Campinas (SP) }\end{array}$ & $\begin{array}{l}\text { Cadernos CEDES } \\
\text { (ISSN 1678-7110) }\end{array}$ \\
\hline $\begin{array}{l}\text { Relações entre leitura, escrita e } \\
\text { alfabetização/letramento científico: um } \\
\text { levantamento bibliográfico em periódicos } \\
\text { nacionais da área de ensino de Ciências }\end{array}$ & $\begin{array}{l}\text { SUISSO; } \\
\text { GALIETA (2015) } \\
{[11]}\end{array}$ & $\begin{array}{l}\text { Universidade } \\
\text { Federal do Rio de } \\
\text { Janeiro (RJ) }\end{array}$ & $\begin{array}{l}\text { Ciência \& Educação } \\
\text { (ISSN 1980-850X) }\end{array}$ \\
\hline $\begin{array}{l}\text { Alfabetização científica ou letramento } \\
\text { científico? Interesses envolvidos nas } \\
\text { interpretações da noção de scientific } \\
\text { literacy. }\end{array}$ & CUNHA (2017) [38] & $\begin{array}{l}\text { Universidade } \\
\text { Estadual de } \\
\text { Campinas (SP) }\end{array}$ & $\begin{array}{l}\text { Revista Brasileira de } \\
\text { Educação (ISSN } \\
\text { 1809-449X) }\end{array}$ \\
\hline $\begin{array}{l}\text { Instrumentos de avaliação do letramento } \\
\text { em saúde: revisão de literatura. }\end{array}$ & $\begin{array}{l}\text { MARQUES; LEMOS } \\
\text { (2017) [39] }\end{array}$ & $\begin{array}{l}\text { Universidade } \\
\text { Federal de Minas } \\
\text { Gerais (MG) }\end{array}$ & $\begin{array}{l}\text { Audiology, } \\
\text { Communication. } \\
\text { Research (ISSN } \\
\text { 2317-6431) }\end{array}$ \\
\hline $\begin{array}{l}\text { Letramento funcional em saúde e adesão } \\
\text { à medicação em idosos: revisão } \\
\text { integrativa. }\end{array}$ & $\begin{array}{l}\text { MARTINS; ABREU; } \\
\text { SILVA; SEMEDO; } \\
\text { PELZER; IENCZAK } \\
\text { (2017) [40] }\end{array}$ & $\begin{array}{l}\text { Universidade } \\
\text { Federal do Rio } \\
\text { Grande (RS) }\end{array}$ & $\begin{array}{l}\text { Revista Brasileira de } \\
\text { Enfermagem (ISSN } \\
\text { 1984-0446) }\end{array}$ \\
\hline
\end{tabular}




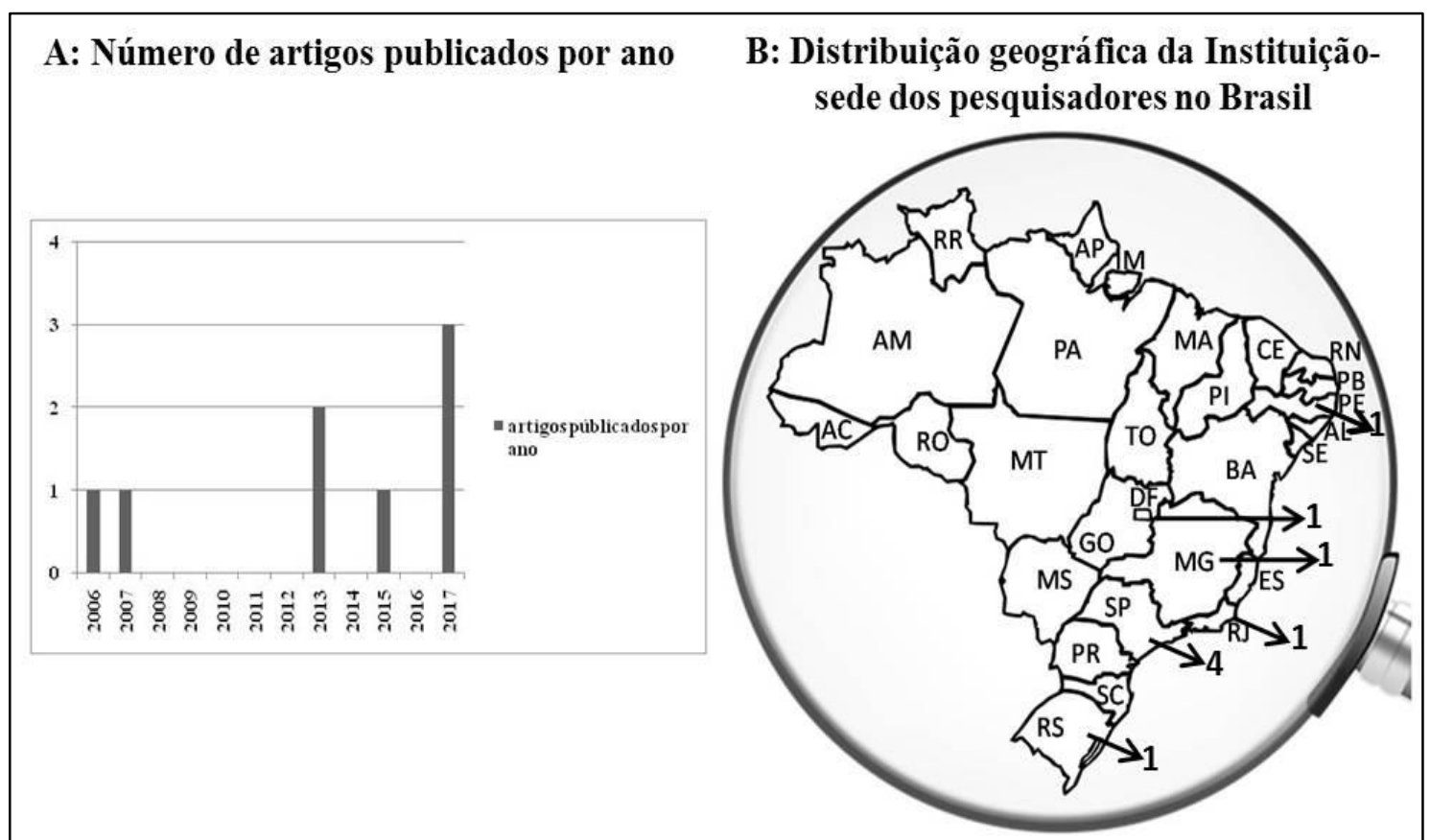

Figura 2: Gráfico demonstrativo da cronologia dos artigos e a distribuição geográfica das instituiçõessede dos pesquisadores encontrados na plataforma Scielo.br, utilizando as palavras-chave: alfabetização científica, letramento.

\subsection{Pesquisa bibliométrica: artigos utilizando as palavras-chave: letramento científico}

Foram encontrados 04 artigos (Tabela 3), distribuídos em duas revistas: 3 na Revista Brasileira de Educação e 1 na Ciência \& Educação. Três desses artigos [11, 24, 38] foram encontrados anteriormente durante a busca pelas outras palavras-chave. A localização geográfica revelou que, os autores que discutem o tema estão concentrados em universidades nos estados do Rio de Janeiro (1); Distrito Federal (1); São Paulo (1); e Tocantins (1). Todos os artigos foram publicados a partir do ano 2007. No entanto, o ano em que houve o maior número de publicações foi o ano de 2017 (2 artigos). Após 2014 (ano da publicação dos ILC no Brasil), foram encontrados 3 artigos. Desses artigos, nenhum deles possui o foco no EFI (Figura 3).

Tabela 3: Listas de artigos encontrados com as palavras-chave: Letramento Cientifico até o ano de 2017 na plataforma Scielo.br.

\begin{tabular}{|c|c|c|c|}
\hline Título do Artigo & $\begin{array}{c}\text { Autores/ ano } \\
\text { da publicação }\end{array}$ & $\begin{array}{c}\text { Universidade } \\
\text { (estado) }\end{array}$ & Revistas (ISSN) \\
\hline $\begin{array}{l}\text { Educação científica na perspectiva de letramento } \\
\text { como prática social: funções, princípios e } \\
\text { desafios. }\end{array}$ & $\begin{array}{l}\text { SANTOS } \\
\text { (2007) [24] }\end{array}$ & $\begin{array}{l}\text { Universidade de } \\
\text { Brasília (DF) }\end{array}$ & $\begin{array}{l}\text { Revista Brasileira } \\
\text { de Educação } \\
\text { (ISSN 1809- } \\
449 X \text { ) }\end{array}$ \\
\hline $\begin{array}{l}\text { Relações entre leitura, escrita e } \\
\text { alfabetização/letramento científico: um } \\
\text { levantamento bibliográfico em periódicos } \\
\text { nacionais da área de ensino de Ciências }\end{array}$ & $\begin{array}{l}\text { SUISSO; } \\
\text { GALIETA } \\
(2015)[11]\end{array}$ & $\begin{array}{l}\text { Universidade } \\
\text { Federal do Rio de } \\
\text { Janeiro (RJ) }\end{array}$ & $\begin{array}{l}\text { Ciência \& } \\
\text { Educação (ISSN } \\
\text { 1980-850X) }\end{array}$ \\
\hline $\begin{array}{l}\text { Alfabetização científica ou letramento científico? } \\
\text { Interesses envolvidos nas interpretações da noção } \\
\text { de scientific literacy. }\end{array}$ & $\begin{array}{l}\text { CUNHA } \\
(2017)[38]\end{array}$ & $\begin{array}{l}\text { Universidade } \\
\text { Estadual de } \\
\text { Campinas (SP) }\end{array}$ & $\begin{array}{l}\text { Revista Brasileira } \\
\text { de Educação } \\
\text { (ISSN 1809- } \\
449 X)\end{array}$ \\
\hline $\begin{array}{l}\text { Formação sustentável do professor no mestrado } \\
\text { profissional }\end{array}$ & $\begin{array}{l}\text { SILVA (2017) } \\
{[41]}\end{array}$ & $\begin{array}{l}\text { Universidade } \\
\text { Federal de } \\
\text { Tocantins (TO) }\end{array}$ & $\begin{array}{l}\text { Revista Brasileira } \\
\text { de Educação } \\
\text { (ISSN 1809- } \\
449 X \text { ) }\end{array}$ \\
\hline
\end{tabular}




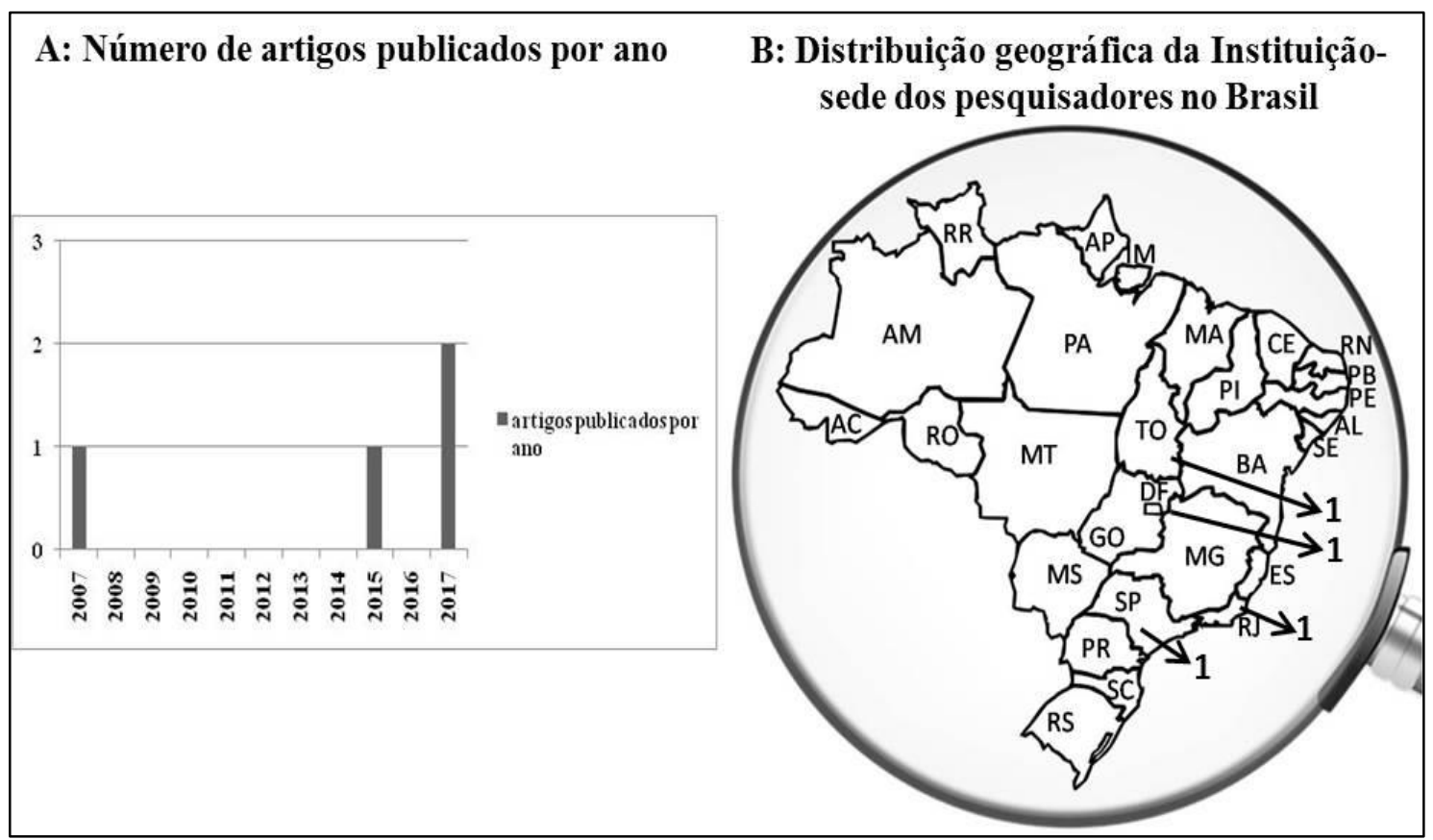

Figura 3: Gráfico demonstrativo da cronologia dos artigos e a distribuição geográfica das instituiçõessede dos pesquisadores encontrados na plataforma Scielo.br, utilizando as palavras-chave: letramento científico.

\subsection{Respostas das diretoras aos assuntos relacionados com AC/LC no EFI}

Foi possível observar que, $7(87,50 \%)$ das oito diretoras conheciam o conceito e temas relacionados com AC/LC (Pergunta 1) e 100\% delas consideram os programas de AC/LC importantes para a formação de alunos mais conscientes e positivamente atuantes na sociedade. Todas elas (100\%) também consideram que alunos do EFI estão aptos a iniciarem metodologias com experimentação no ensino em Ciências e que o investimento em programas de AC/LC é essencial para construção de uma sociedade mais igualitária (Perguntas 2, 3, 4). Quatro (50\%) das oito diretoras responderam que existem projetos de discussão e melhoria do ensino em ciências no PPP da escola (Pergunta 5). Quatro (50\%) das oito diretoras relataram haver dinheiro para execução de projetos experimentais e feiras de ciências na escola (Pergunta 6). Porém, todas as diretoras $(100 \%)$ responderam não haver laboratório nas escolas (Pergunta 7). Sete diretoras $(87,50 \%)$ defenderam a capacitação dos professores para realizar aulas experimentais e inovadoras em Ciências (Pergunta 8) e todas elas (100\%) responderam que os órgãos superiores de ensino deveriam ser responsáveis por oferecer a capacitação para estes docentes (Pergunta 9). Seis $(75 \%)$ das oito diretoras assumiram que não haveria resistência dos docentes para a implantação de metodologias ativas e aulas experimentais em Ciências (Pergunta 10) (Tabela 4). 
Tabela 4: Questionários e resultados das respostas das diretoras.

\begin{tabular}{|c|c|c|c|}
\hline \multirow{2}{*}{\multicolumn{2}{|c|}{ Perguntas }} & \multicolumn{2}{|c|}{$\begin{array}{l}\text { Respostas } \\
(\%)\end{array}$} \\
\hline & & sim & Não \\
\hline 1 & Você conhece a definição do termo e o conceito de alfabetização e letramento científico? & 87,5 & 12,5 \\
\hline 2 & $\begin{array}{l}\text { Indivíduos alfabetizados e letrados cientificamente são mais socialmente conscientes? Eles } \\
\text { possuem maior capacidade de se integrar a sociedade e podem atuar positivamente na } \\
\text { transformação da sociedade? }\end{array}$ & 100 & 0 \\
\hline 3 & $\begin{array}{l}\text { Autores defendem que os alunos do Ensino Fundamental I (EFI) já estão aptos a experienciar } \\
\text { ambientes de experimentação em ciências e tecnologias. Você acredita que nesta faixa etária } \\
\text { estes alunos já possuem capacidade de realizar experimentos, maquetes e desenvolverem } \\
\text { projetos envolvendo temas científicos e tecnológicos? }\end{array}$ & 100 & $\mathbf{0}$ \\
\hline 4 & $\begin{array}{l}\text { Você acredita que investir na alfabetização e no letramento e conhecimento científico dos } \\
\text { indivíduos, desde o EFI, sejam importantes para a construção de uma sociedade mais igualitária } \\
\text { em relação às oportunidades de estudo, trabalho e organização econômico-político-social? }\end{array}$ & 100 & $\mathbf{0}$ \\
\hline 5 & $\begin{array}{l}\text { Existem, no PROJETO POLÍTICO PEDAGÓGICO (PPP) da instituição, propostas para a } \\
\text { discussão e a melhoria dos métodos para aumentar o nível de letramento científico dos alunos } \\
\text { desde o EFI? }\end{array}$ & 50 & 50 \\
\hline 6 & $\begin{array}{l}\text { Atualmente, a escola de ensino fundamental I, em que atua, dispõe de recursos financeiros para } \\
\text { a realização projetos, como as feiras de ciências? }\end{array}$ & 50 & 50 \\
\hline 7 & $\begin{array}{l}\text { A escola em que você atua possui laboratório e materiais para elaboração de aulas práticas em } \\
\text { ciências? }\end{array}$ & $\mathbf{0}$ & 100 \\
\hline 8 & $\begin{array}{l}\text { Você considera importante realizar a capacitação dos docentes para o ensino de Ciências } \\
\text { baseado na experimentação? }\end{array}$ & 87,5 & 12,5 \\
\hline 9 & $\begin{array}{l}\text { Você acredita que seria necessário que órgãos superiores de ensino, como o departamento de } \\
\text { educação, secretaria de educação, etc., oferecessem cursos de capacitação aos docentes, para } \\
\text { habilitá-los para desenvolverem o ensino de ciências por meio de projetos e experimentação? }\end{array}$ & 100 & 0 \\
\hline 10 & $\begin{array}{l}\text { Se não existir na instituição e fosse proposto, realizar a metodologia ativa de ensino em } \\
\text { Ciências, baseada em projetos e experimentos, você acredita que haveria resistência, dos } \\
\text { docentes? }\end{array}$ & 75 & 25 \\
\hline
\end{tabular}

\subsection{Respostas das coordenadoras pedagógicas aos assuntos sobre AC/LC no EF I}

Foi possível observar que, oito ( $89 \%$ ) das nove coordenadoras relataram que conhecem temas relacionados com AC/LC (Pergunta 1). Todas (100\%) consideraram os programas de AC/LC importantes para a formação de alunos mais conscientes e positivamente atuantes na sociedade. Todas elas também consideraram que, alunos do EFI estão aptos a iniciarem metodologias com experimentação no ensino em Ciências e que programas de AC/LC são essenciais para uma sociedade mais igualitária (Perguntas 2, 3, 4). Das nove coordenadoras, seis $(67 \%)$ responderam que não existe menção a um projeto de discussão e melhoria do ensino em Ciências no PPP da escola (Pergunta 5). Resultado que difere do observado no questionário das diretoras. Sete (78\%) coordenadoras reconheceram que os cursos de graduação não capacitam os graduandos para realizar atividades de experimentação (como as feiras de ciências) com os alunos (Pergunta 6). Todas as coordenadoras (100\%) defenderam que os órgãos superiores de ensino deveriam oferecer a capacitação para que os docentes se habilitassem para executar projetos de experimentação nas aulas de Ciências (Pergunta 7). Todas (100\%) as coordenadoras consideraram importantes as visitas a espaços científico-culturais como trilhas ecológicas, zoológicos, etc. (Pergunta 8). Oito delas (89\%) também consideraram executáveis as metodologias ativas de ensino com alunos do EFI (Pergunta 9). Discordando das respostas das diretoras, seis (67\%) das coordenadoras pedagógicas responderam que poderia haver resistência de docentes para a implantação da metodologia ativa de ensino nas aulas de Ciências (Pergunta 10) (Tabela 5). 
Tabela 5: Questionários simplificados e os resultados das respostas das coordenadoras pedagógicas.

\begin{tabular}{|c|c|c|c|}
\hline \multirow{2}{*}{\multicolumn{2}{|c|}{ Perguntas }} & \multicolumn{2}{|c|}{$\begin{array}{c}\text { Respostas } \\
(\%)\end{array}$} \\
\hline & & Sim & Não \\
\hline 1 & Você conhece a definição do termo e o conceito de alfabetização e letramento científico? & 89 & 11 \\
\hline 2 & $\begin{array}{l}\text { Você acredita que indivíduos considerados alfabetizados e letrados cientificamente são mais } \\
\text { socialmente conscientes, possuem maior capacidade de se integrar a sociedade e podem atuar } \\
\text { positivamente na transformação da sociedade? }\end{array}$ & 100 & $\mathbf{0}$ \\
\hline 3 & $\begin{array}{l}\text { Autores defendem que os alunos do Ensino Fundamental I (EFI) já estão aptos a experienciar } \\
\text { ambientes de experimentação em ciências e tecnologias. Você acredita que nesta faixa etária } \\
\text { estes alunos já possuem capacidade de realizar experimentos, maquetes e desenvolverem } \\
\text { projetos envolvendo temas científicos e tecnológicos? }\end{array}$ & 100 & $\mathbf{0}$ \\
\hline 4 & $\begin{array}{l}\text { Você acredita que investir na alfabetização e no letramento e conhecimento científico dos } \\
\text { indivíduos, desde o EFI, sejam importantes para a construção de uma sociedade mais } \\
\text { igualitária em relação às oportunidades de estudo, trabalho e organização econômico-político- } \\
\text { social? }\end{array}$ & 100 & $\mathbf{0}$ \\
\hline 5 & $\begin{array}{l}\text { Existem, no PROJETO POLÍTICO PEDAGÓGICO (PPP) da instituição, propostas para a } \\
\text { discussão e a melhoria dos métodos para aumentar o nível de letramento científico dos alunos } \\
\text { desde o EFI? }\end{array}$ & 33 & 67 \\
\hline 6 & $\begin{array}{l}\text { Atividades que priorizam e facilitam o letramento científico envolvem aulas mais dinâmicas, } \\
\text { ativas e experimentais. Em sua opinião, os cursos de graduação capacitam o futuro professor, } \\
\text { a aplicar projetos envolvendo atividades de experimentação, como o desenvolvimento de } \\
\text { projetos e feiras de Ciências? }\end{array}$ & 22 & 78 \\
\hline 7 & $\begin{array}{l}\text { Você acredita que seria necessário que órgãos superiores de ensino, como o departamento de } \\
\text { educação, secretaria de educação, etc., oferecessem cursos de capacitação aos docentes, para } \\
\text { habilitá-los para desenvolverem o ensino de ciências por meio de projetos e experimentação? }\end{array}$ & 100 & 0 \\
\hline 8 & $\begin{array}{l}\text { Você acredita ser importante proporcionar aos alunos, visitas a espaços de difusão científica e } \\
\text { cultural? (Biblioteca, Zoológico, Museu de ciência e tecnologia, Feira ou Olimpíadas de } \\
\text { Ciências, Museu de artes, Trilhas ecológicas, etc.). }\end{array}$ & 100 & 0 \\
\hline 9 & $\begin{array}{l}\text { Em relação à metodologia do ensino de Ciências no EFI, você considera importante ou } \\
\text { executável a metodologia ativa, na qual, os alunos por meio de questões e problemas do } \\
\text { mundo que o cercam, possam ser incentivados a levantar hipóteses em relação à problemática } \\
\text { e assim empenhar-se a buscar respostas baseadas na reflexão e criticidade dos acontecimentos } \\
\text { do mundo? }\end{array}$ & 89 & 11 \\
\hline 10 & $\begin{array}{l}\text { Se não existir na instituição e fosse proposto, realizar a metodologia ativa de ensino em } \\
\text { Ciências, baseada em projetos e experimentos, você acredita que haveria resistência, dos } \\
\text { docentes? }\end{array}$ & 67 & 33 \\
\hline
\end{tabular}

\subsection{Respostas das docentes aos assuntos relacionados com a AC no EFI}

Foi possível observar nas respostas ao questionário 3, que, 32 das $42(76 \%)$ professoras entrevistadas responderam que conhecem temas relacionados com AC/LC (Pergunta 1). 36 professoras $(88 \%)$ também consideraram os programas de AC/LC importantes para a formação de alunos conscientes e positivamente atuantes na sociedade. Neste item houve uma abstenção (Pergunta 2). 40 docentes (95\%) consideraram que, alunos do EFI estão aptos a iniciarem metodologias com experimentação no ensino em Ciências (Pergunta 3). 39 delas (93\%) consideraram importante o investimento em programas de AC/LC desde o EFI (Pergunta 4). Em relação a capacitação nos cursos de graduação para aplicar projetos de experimentação, houve uma maioria $(60 \%)$ que considerou que os cursos de graduação não atendem estes requisitos durante a formação dos futuros docentes (Pergunta 5). 35 docentes (83\%) consideraram que os órgãos superiores de ensino deveriam ser os responsáveis por capacitar os docentes para executar metodologias e projetos de experimentação em Ciências (Pergunta 6). 39 docentes (93\%) revelaram que gostariam de realizar aulas de Ciências em laboratórios (Pergunta 7). As professoras foram unânimes (100\%) em afirmar que visitas a espaços de difusão científicoculturais são importantes para os alunos (Pergunta 8). 36 entrevistadas (86\%) consideraram aplicável a Aprendizagem Baseada em Problemas para o ensino de Ciências no EFI. 40 professoras $(97 \%)$ consideraram importante a execução de metodologia ativa, onde os alunos possam levantar hipóteses em relação a problemática, empenhando-se na resolução de problemas relacionados as Ciências da Natureza (Pergunta 10). Nas questões 9-10 houve uma abstenção para cada item (Tabela 6). 
Tabela 6: Questionários simplificados e os resultados das respostas das docentes.

\begin{tabular}{|c|c|c|c|}
\hline \multirow{2}{*}{\multicolumn{2}{|c|}{ Pergunta }} & \multicolumn{2}{|c|}{$\begin{array}{l}\text { Respostas } \\
(\%)\end{array}$} \\
\hline & & Sim & Não \\
\hline $\mathbf{1}$ & Você conhece a definição do termo e o conceito de alfabetização e letramento científico? & 76 & 24 \\
\hline 2 & $\begin{array}{l}\text { Você acredita que indivíduos considerados alfabetizados e letrados cientificamente são mais } \\
\text { socialmente conscientes, possuem maior capacidade de se integrar a sociedade e podem atuar } \\
\text { positivamente na transformação da sociedade? }\end{array}$ & 88 & 12 \\
\hline 3 & $\begin{array}{l}\text { Autores defendem que os alunos do Ensino Fundamental I (EFI) já estão aptos a experienciar } \\
\text { ambientes de experimentação em ciências e tecnologias. Você acredita que nesta faixa etária } \\
\text { estes alunos já possuem capacidade de realizar experimentos, maquetes e desenvolverem } \\
\text { projetos envolvendo temas científicos e tecnológicos? }\end{array}$ & 95 & 5 \\
\hline 4 & $\begin{array}{l}\text { Você acredita que investir na alfabetização e no letramento e conhecimento científico dos } \\
\text { indivíduos, desde o EFI, sejam importantes para a construção de uma sociedade mais igualitária } \\
\text { em relação às oportunidades de estudo, trabalho e organização econômico-político-social? }\end{array}$ & 93 & 7 \\
\hline 5 & $\begin{array}{l}\text { Atividades que priorizam e facilitam o letramento científico envolvem aulas mais dinâmicas, } \\
\text { ativas e experimentais. Em sua opinião, os cursos de graduação capacitam o futuro professor, } \\
\text { a aplicar projetos envolvendo atividades de experimentação, como o desenvolvimento de } \\
\text { projetos e feiras de Ciências? }\end{array}$ & 40 & 60 \\
\hline 6 & $\begin{array}{l}\text { Você acredita que seria necessário que órgãos superiores de ensino, como o departamento de } \\
\text { educação, secretaria de educação, etc., oferecessem cursos de capacitação aos docentes, para } \\
\text { habilitá-los para desenvolverem o ensino de ciências por meio de projetos e experimentação? }\end{array}$ & 83 & 17 \\
\hline 7 & $\begin{array}{l}\text { Você gostaria de realizar projetos e aulas práticas de experimentação em ciências em } \\
\text { laboratórios com seus alunos? }\end{array}$ & 93 & 7 \\
\hline 8 & $\begin{array}{l}\text { Você acredita ser importante proporcionar aos alunos, visitas a espaços de difusão científica e } \\
\text { cultural? (Biblioteca, Zoológico, Museu de ciência e tecnologia, Feira ou Olimpíadas de } \\
\text { Ciências, Museu de artes, Trilhas ecológicas, etc.). }\end{array}$ & 100 & 0 \\
\hline 9 & $\begin{array}{l}\text { Um método ativo de ensino que vem sendo utilizado positivamente no ensino de ciências da } \\
\text { saúde é a Aprendizagem Baseada em Problemas (ABP, ou em inglês, PBL- Problem Based } \\
\text { Learning). Este tipo de metodologia pode ser utilizado no ensino de ciências com alunos do } \\
\text { EFI? }\end{array}$ & 88 & 12 \\
\hline 10 & $\begin{array}{l}\text { Em relação à metodologia do ensino de Ciências no EFI, você considera importante ou } \\
\text { executável a metodologia ativa, na qual, os alunos por meio de questões e problemas do mundo } \\
\text { que o cercam, possam ser incentivados a levantar hipóteses em relação à problemática e assim } \\
\text { empenhar-se a buscar respostas baseadas na reflexão e criticidade dos acontecimentos do } \\
\text { mundo? }\end{array}$ & 97 & 3 \\
\hline
\end{tabular}

\section{DISCUSSÃO}

Este trabalho revelou que, a temática sobre AC/LC não possui número expressivo de artigos publicados na plataforma Scielo.br. Esse número ainda é menor quando se limita a pesquisa à discussão da temática no EFI. No entanto, deve ser levada em consideração a existência de publicações indexadas em outras bases, as quais não foram objeto do presente estudo. Além disso, as discussões envolvendo alfabetização científica, muitas vezes aparecem em publicações envolvendo o "Ensino de Ciências" e não aparecem na busca pelas palavras-chave empregadas neste estudo. Em relação à opinião dos profissionais do EFI do ensino público, nota-se o conhecimento e importância dada à temática da $\mathrm{AC} / \mathrm{LC}$ e a preocupação em inserir metodologias inovadoras no ensino de ciências, através de cursos de capacitação. Fatores negativos encontrados na pesquisa foram, a ausência de laboratórios nas escolas, embora exista o interesse das docentes em realizar aulas práticas e experimentais em laboratórios. Fator importante a ser levado em consideração foi o relato da maioria de docentes e coordenadoras pedagógicas de que os cursos de graduação não capacitam os graduandos para utilizar metodologias ativas e experimentais no ensino de Ciências no EFI.

O estudo bibliométrico realizado neste estudo se mostrou eficaz por fazer um levantamento de publicações em língua portuguesa e realizadas por autores brasileiros, uma vez que, o foco das observações e a justificativa do trabalho se limitaram aos problemas e indicadores dessa população. Notou-se que, os conceitos: AC/LC ainda carecem de definições mais apropriadas para o nosso idioma, uma vez que, ambos os termos: alfabetização e letramento derivam do mesmo vocábulo (literacy) em inglês $[5,11,38,42]$. 
Um fator relevante da busca bibliográfica foi o número não expressivo de pesquisadores discutindo a temática da $\mathrm{AC} / \mathrm{LC}$, ocorrendo em um limitado número de estados brasileiros (10 estados). Porém, salienta-se que, a busca em outras plataformas de indexação pode revelar um número maior de trabalhos científicos publicados. Outro destaque se refere à geodistribuição das instituições-sede dos autores, as quais se concentram principalmente nos estados de São Paulo e Rio de Janeiro, que pertencem à região Sudeste do país, a qual é reconhecidamente a região com maior desenvolvimento científico e tecnológico do país. Em quantidade de artigos publicados, os presentes resultados se assemelham ao estudo realizado por Suisso e Galieta (2015) [11], embora os objetivos finais dos dois trabalhos não se assemelhem. As autoras alertam para que, as pesquisas sobre AC/LC sejam rigorosas no delineamento dos referenciais teóricos e conceitos envolvidos, para que possam contribuir efetivamente com a melhoria do Ensino de Ciências. Lorenzetti e Delizoicov (2001) [5] descrevem que, resgates bibliométricos dos trabalhos desenvolvidos no Brasil sobre o tema AC/LC propiciam o estabelecimento de uma compreensão e busca por soluções e mudanças no processo de $\mathrm{AC} / \mathrm{LC}$ a ser realizado nas séries iniciais do EFI. No entanto, os autores Lorenzetti e Delizoicov (2001) [5] enfatizaram que, a literatura relativa ao tema alfabetização científica possui preocupações mais abrangentes do que a educação científica nas séries iniciais, e neste seguimento, são praticamente ausentes referências explicitas que têm como foco o ensino nesta fase de formação dos alunos, o que concorda com nossos resultados, embora os autores tenham discutido o fato no início dos anos 2000. Na presente pesquisa, se observou que muitos autores discutem o conceito mais apropriado para AC/LC; discutem metodologias de ensino; também discutem a temática na educação de jovens e adultos; discutem a temática no ensino de disciplinas específicas do ensino médio, como química e física; também discutem o tema com foco na saúde e educação ambiental, entre outros, como se pode observar nas tabelas 1,2 e 3 .

No presente trabalho, buscou-se pesquisas relacionadas ao EFI, por se tratar de indivíduos com faixa etária variando entre 6 e 10 anos. Nesta idade, as crianças estão na fase de descobertas, em processo de alfabetização e letramento na língua materna. A contribuição do ensino de Ciências Naturais nas séries iniciais do EFI é importantíssima para o processo de alfabetização dos alunos e para a sociedade [5]. O objetivo final das séries iniciais é aprender a ler e a escrever na língua materna. Dessa maneira, fazer uso do ensino de Ciências para que os alunos aprendam a ler e a escrever permite que, os alunos sejam "alfabetizados cientificamente" [11].

$\mathrm{Na}$ contramão dessa perspectiva, o exame PISA [13] revelou que, os estudantes brasileiros de até 15 anos de idade ficaram na $63^{\mathrm{a}}$ posição entre as 70 nações avaliadas para o conhecimento em Ciências. O ILC (2014) [10] também alertou sobre o baixo nível dos Indicadores de Letramento Científico da população brasileira. Ao final, o Instituto responsável pela pesquisa [10] destacou em documento que, a sociedade pede urgência, para pensar e propor a reinvenção da educação escolar, sobretudo o ensino de Ciências. Baseado no presente estudo parece que, nos últimos anos não houve uma maior mobilização por parte dos pesquisadores brasileiros em discutir "especificamente" o tema ou metodologias para a AC/LC, principalmente quando se refere ao EFI. Mas, voltamos a afirmar que, não desconsideramos publicações em outras bases de indexação de periódicos. Além disso, é sabido que, as pesquisas envolvem tempo para serem realizadas e não se pode excluir a possibilidade de já haver maior mobilização entre as autoridades e os pesquisadores atuantes nas Ciências, as quais poderão ser confirmadas por discussões e publicações científicas nos próximos anos, além da finalidade maior que seria a mobilização em prol de políticas públicas que pudessem atender a demanda nacional por melhorias na educação científica.

A AC trata-se de uma meta a ser alcançada e requer práticas pedagógicas que viabilizem seus objetivos. Lorenzetti e Delizoicov (2001) [5] e Brito e Fireman (2016) [21] propõe o uso do ensino de Ciências por investigação, para que os alunos se envolvam efetivamente com a compreensão da Ciência, por meio da resolução de problemas reais, com espaço e tempo para questionamentos, testes de hipóteses, trocas de informações e sistematização de ideias. De acordo com Brito e Fireman (2016) [21], o ensino por investigação mostra-se uma metodologia adequada à promoção da alfabetização científica. Esta metodologia é defendia porque os alunos apresentam empatia pelo problema a ser resolvido, estimulando sua curiosidade, promovendo o desenvolvimento de habilidades reflexivas e intelectuais. Estes requisitos tem se revelado essenciais à medida que 
adentramos a quarta revolução, ou revolução 4.0, reconhecida pelo amplo acesso à informação e pela velocidade na disseminação dos conhecimentos científicos e tecnológicos. Em sua essência, a quarta revolução industrial não é definida por um conjunto de tecnologias emergentes em si mesmas, mas a transição em direção a novos sistemas que foram construídos sobre a infraestrutura da revolução digital [1]. Esses fatores exigem que os indivíduos sejam capazes de usar socialmente o conhecimento científico-tecnológico, como forma de exercer sua cidadania e desenvolver competências para aplicação no cotidiano e no mercado de trabalho [2]. Como forma de potencializar essas competências, os parâmetros curriculares nacionais (PCN) [43] para o ensino de Ciências Naturais recomenda também que, o professor incentive leituras (literatura infantil, peças teatrais, notícias ou textos científicos, em revistas e jornais) sobre assuntos relacionados a Ciências Naturais. Atualmente outras ferramentas também podem ser utilizadas, tais como: blogs, canais de Youtube, sites, documentários, aplicativos de celular, entre outras novas tecnologias de informação e conhecimento que surgiram após a publicação dos PCNs [43]. Atualmente, para as áreas das Ciências da Natureza, as BNCC [44] enfatizam que, ao longo do Ensino Fundamental, deve-se prezar pelo compromisso com o desenvolvimento do LC, que envolve a capacidade de compreender e interpretar o mundo (natural, social e tecnológico), e também de transformá-lo com base nos aportes teóricos e processuais das ciências. Para a Base Nacional Comum Curricular (BNCC), aprender ciência por si só não é a finalidade do letramento, mas, sim, o desenvolvimento da capacidade de atuação social, considerado imprescindível para o pleno exercício da cidadania.

$\mathrm{Na}$ segunda parte deste trabalho, verificou-se que, a grande maioria das entrevistadas afirmou que, AC/LC são importantes elementos para a formação de alunos mais críticos e aptos a um mundo globalizado e em constantes mudanças científico-tecnológicas, indo ao encontro da teoria defendida por Schwab [1] em sua obra "A quarta Revolução Industrial", que destaca a importância do LC, uma vez que, o desenvolvimento científico e tecnológico resulta em novos e melhores produtos e serviços ao mesmo tempo em que pode promover desequilíbrios na natureza e na sociedade, além de trazer perigos para a própria manutenção da vida na Terra [1]. Por esta razão, atualmente, tem-se exigido das sociedades, investimento estratégico e dirigido, na área da informação, ciência e tecnologia, visando fomentar as inovações científico-tecnológicas, passando pelo investimento na formação dos indivíduos [2]. Lorenzetti e Delizoicov (2001) [5] defendem a premissa de que a $\mathrm{AC}$ pode e deve ser desenvolvida desde o início do processo de escolarização. O PCN [43] para ensino de Ciências também sugere a inserção da AC nas séries iniciais do EFI. Atualmente, a BNCC [44] tem uma preocupação maior com o LC, desta maneira, defendem que, o LC deve propiciar aos alunos, debater e tomar posição sobre alimentos, medicamentos, combustíveis, transportes, comunicações, saneamento e manutenção da vida na Terra, entre muitos outros temas. Para tanto, são imprescindíveis tanto conhecimentos éticos, políticos e culturais quanto científicos. As respostas das entrevistadas no presente estudo concordam também com estas afirmações. A AC constitui-se como uma das grandes linhas de investigação no ensino de Ciências da Natureza. E, esse movimento, relaciona-se à mudança dos objetivos do ensino de Ciências em direção à formação da alfabetização para a cidadania, possuindo um papel relevante na sociedade atual [23, 44, 45].

Em relação à metodologia ativa de ensino, observou-se que, a maioria entende que esta metodologia é importante e pode ser aplicada desde o EFI para as aulas de Ciências, concordando com a proposta da BNCC [44] que propõe atividades de investigação e experimentação para uma aprendizagem significativa na área das Ciências Naturais. Morais e Paiva (2014) [3] destacam que, é crucial que a educação em Ciências da Natureza, que passa pelo ensino dessas ciências, contribua para problematizar o saber e contextualizar os conhecimentos, de modo que os alunos possam apropriar-se deles e mobilizá-los convenientemente em diversas situações com as quais são confrontados no cotidiano. Sendo assim, é fundamental preparar os alunos para pensar criticamente em um mundo de contínuas e aceleradas transformações científicas e tecnológicas e motivá-los para se envolverem na aprendizagem das ciências, visando potencializar a busca ativa pelo conhecimento. Neste sentido, as metodologias ativas de ensino podem ser úteis para proporcionar uma aprendizagem significativa na área das Ciências da Natureza.

A maioria das entrevistadas também sugeriram programas de capacitação dos docentes para aplicar métodos de experimentação no ensino de Ciências, uma vez que, assumem que os cursos 
de graduação acabam não atingindo o objetivo de capacitá-los para este tipo de metodologia, sobretudo, no EFI. A oferta de cursos de capacitação, com abordagens inovadoras, poderiam privilegiar a experimentação e o método ativo de ensino, como defendido por Nigro e Azevedo (2011) [20] e Neves et al. (2016) [12]. Lorenzetti e Delizoicov (2001) [5] e Neves et al. (2016) [12] afirmam que, a formação inicial e continuada de professores são problemas que surgem devido às especificidades do ensino de Ciências da Natureza nas séries iniciais, uma vez que, na maioria dos casos, é desenvolvida por professores polivalentes, os quais são responsáveis por diferentes áreas do saber e muitas vezes não possuem capacitação para tal tarefa. Assim, as aulas de Ciências da Natureza acabam utilizando metodologias precárias e ultrapassadas, como aulas expositivas e o ensino "decoreba", se limitando simplesmente em ensinar termos científicos [46]. Estes fatos auxiliam na compreensão dos resultados da pesquisa da agência Datafolha encomendada pela Agência FAPESP, a qual revelou que um quarto dos entrevistados respondeu que a escola foi a responsável pela perda do interesse pelas Ciências Naturais [15]. Neste sentido, a BNCC [44] procura tornar o ensino de Ciências da Natureza mais estimulante para os alunos, na medida em que propõe a investigação e a experimentação como ferramentas didáticas para favorecer uma aprendizagem significativa nesta área do conhecimento. Talvez a discussão sobre estas metodologias devam ser estimuladas em trabalhos científicos, pois a pesquisa sobre a percepção sobre ciência e tecnologia realizada pelo Centro de Gestão e Estudos Estratégicos (CGEE) e o Ministério da Ciência, Tecnologia e Inovação (MCTI) [14], revelaram que, os brasileiros possuem interesse sobre assuntos de ciência e tecnologia. Porém, outra discussão necessita de maiores aportes científicos e até mesmo discussão de propostas políticas para se estimular a popularização e difusão da ciência, uma vez que, a maioria dos entrevistados continua com acesso escasso à informação científica e tecnológica, especialmente quando analisados indivíduos das camadas sociais de menor escolaridade e renda [14].

Krasilchik (2011) [6] considera que, é necessário o estudo de fatores que agem negativamente sobre o ensino de Ciências. Dessa forma, todo docente, seguramente deve analisar os elementos que interferem negativamente no ensino atual, o qual está distante de ser satisfatório, apesar de esforços isolados de algumas instituições e indivíduos para aperfeiçoá-lo. Observou-se no presente estudo que, houve uma divergência nas respostas de diretoras e coordenadora sobre a presença de medidas visando à adaptação e melhoria do ensino de Ciências no PPP da escola. $50 \%$ das diretoras e $67 \%$ das coordenadoras pedagógicas afirmaram não haver proposta sobre programas de AC/LC no PPP das escolas onde atuam. O fato pode ser atribuído pelo fato delas divergirem sobre conhecerem ou não o termo $\mathrm{AC} / \mathrm{LC}$, o qual também é discutido por alguns autores [5, 11, 38]. Porém Lorenzetti e Delizoicov (2001) [5] retratam a importância do planejamento do currículo escolar para a inserção da AC/LC no PPP das escolas.

A maioria das diretoras confirmou a existência de recursos financeiros para a execução de projetos com experimentação e feiras de ciências. Ao mesmo tempo, nenhuma escola apresentou laboratórios apropriados para execução de projetos e aulas experimentais em Ciências. Como alternativa, as escolas poderiam estimular a $\mathrm{AC} / \mathrm{LC}$ por meio de outras ferramentas, tais como: blogs, canais de Youtube, sites, documentários, jogos educativos, aplicativos de celular e outras novas tecnologias de informação e conhecimento, além de, visitas a espaços de difusão científicocultural, tais como, trilhas ecológicas, visitas a zoológicos e museus, olimpíadas e feiras de ciência, etc. [19] as quais foram defendidas por $100 \%$ das entrevistadas.

Finaliza-se essa discussão, destacando que, o ser humano foi capaz de crescer e explorar o mundo; revolucionou a sociedade com novas descobertas e tecnologias. No entanto, ao longo de suas conquistas, o homem perdeu sua integração com a natureza. A educação tradicional em Ciências não tem mais preparado adequadamente os indivíduos para a complexa realidade científico-tecnológica global [6,7], e nem preparado adequadamente os indivíduos para a cidadania e sustentabilidade [7], ou mesmo buscado a inserção social por meio de eficazes programas de AC/LC [23]. Então, o ensino de ciências precisa ser repensado e reinventado nos cursos de formação de professores, ao mesmo tempo em que, novas metodologias baseadas em métodos ativos e experimentais vão sendo incorporados aos currículos do EFI em escolas. Enfim, se a sociedade brasileira almeja estar na vanguarda do conhecimento científico e tecnológico, ela precisa se unir em torno desse ideal, para propor a implantação de um programa eficaz de AC/LC desde o EFI. Um programa que vise capacitar os cidadãos a participarem e se inserirem no 
universo científico-tecnológico em que vivemos. Isto possibilitaria maiores inovações em todos os setores da sociedade, mas somente poderia ocorrer através de políticas de democratização da ciência.

\section{CONCLUSÃO}

Como pode ser observado, através da metodologia empregada, não foi encontrado um número expressivo de publicações discutindo "especificamente" o tema AC/LC no EFI no Brasil. Grande parte das publicações encontradas trata-se de levantamentos bibliográficos e discussões sobre a terminologia da AC/LC, dando subsídio para pesquisas práticas envolvendo o assunto, o qual também é discutido em artigos sobre o ensino de ciências. Dos trabalhos encontrados, poucos são os que focam na formação científica desde os primeiros anos do EFI. O levantamento bibliométrico de publicações parece um caminho interessante para colaborar com discussões e debates em torno do tema AC/LC. Estas pesquisas permitem ampliar o debate sobre a promoção da AC/LC, como filosofia de ensino, visando formar alunos críticos, reflexivos, exploradores, criativos e capacitados para transformar conscientemente o mundo.

A segunda parte da pesquisa proporcionou entender a opinião de profissionais que atuam no EFI em relação a temas que envolvem o ensino de Ciências e a AC/LC e pode ser útil para a discussão de propostas e implantação de novos métodos de ensino em Ciências Naturais. A ampla maioria das entrevistadas conhecia a temática envolvendo AC/LC e consideraram importantes a AC/LC dos indivíduos e acreditam que a AC/LC dos indivíduos possui reflexos positivos na sociedade. A maioria também defende os métodos ativos de ensino e a experimentação em Ciências Naturais no EFI. A maioria também apoia a proposta de metodologias inovadoras de ensino em Ciências Naturais. No entanto, a maioria também defende a capacitação dos docentes que já atuam no ensino público brasileiro para utilizarem metodologias experimentais em suas aulas. Um fator relevante e negativo encontrado nas respostas de profissionais entrevistadas foi a declaração de que nenhuma das escolas possui um laboratório e algumas escolas também não possuem estratégias para melhorar os resultados do ensino de Ciências Naturais e consequentemente a AC/LC. Outro fator negativo foi a resposta, embora da minoria, de que poderia haver resistência de docentes em relação a aplicação da metodologia experimental no EFI. A maioria das entrevistadas também responderam que, os cursos de graduação, na grande maioria dos casos, não capacitam os professores que atuam no EFI a atuar com metodologias experimentais para o ensino de Ciências no EFI. A maioria também apoia o uso de novas ferramentas tecnológicas de ensino e visitas a espaços informais de educação, tais como zoológicos, trilhas ecológicas, museus, etc.

\section{AGRADECIMENTOS}

Os autores agradecem ao Conselho Nacional de Pesquisa (CNPq) (Processo número 157480/2017-8) pelo financiamento desta pesquisa. Também agradecem todas as entrevistadas na pesquisa pelo apoio na discussão dos resultados deste trabalho.

\section{REFERÊNCIAS BIBLIOGRÁFICAS}

1. Schwab K. A Quarta Revolução Industrial. São Paulo: Edipro; 2016. 160p.

2. Borges MN. Ciência, Tecnologia e inovação para o desenvolvimento do Brasil. Scientia Plena. 2016;12(8):1-11, doi:10.14808/sci.plena.2016.089901.

3. Morais C, Paiva J. Olhares e reflexões contemporâneas sobre o triângulo sociedade-educaçãotecnologias e suas influências no ensino das ciências. Educ Pesq. 2014;40(4):953-64, doi:10.1590/s1517-97022014121411.

4. Coordenação De Comunicação Social CNPQ. Seminário discute ação internacional no Brasil para CT\&I. Disponível em: <http://cnpq.br/web/guest/noticiasviews//journal_content/56_INSTANCE_a6MO/10157/5954010. Acesso em: 06 de janeiro de 2018. 
5. Lorenzetti L, Delizoicov D. Alfabetização científica no contexto das séries iniciais. Ens Pesq Educ Ciênc. 2001; 3(1):45-61, doi:10.1590/1983-21172001030104.

6. Krasilchik M. Prática do Ensino de Biologia. 4ed. São Paulo: Editora da Universidade de São Paulo; 2011. 199p.

7. Kondrat H, Maciel MD. Educação ambiental para a escola básica: contribuições para o desenvolvimento da cidadania e da sustentabilidade. Rev Bras Educ. 2013;18(55):825-46, doi:10.1590/S141324782013000400002.

8. Scortegagna A. Alfabetização Científica e o desenvolvimento de um país. Revista Época. Disponível em: <http://epoca.globo.com/vida/noticia/2015/04/alfabetizacao-cientifica-e-o-desenvolvimento-deum-pais.html> Acesso em: 01 de novembro de 2017.

9. Soares MB. Alfabetização e letramento. 7ed. São Paulo: Contexto; 2017. 123p.

10. ILC. Indicador de Letramento Científico. São Paulo: Instituto ABRAMUNDO; 2014. 43p.

11. Suisso C, Galieta T. Relações entre leitura, escrita e alfabetização/letramento científico: um levantamento bibliográfico em periódicos nacionais da área de ensino de ciências. Ciênc Educ. 2015;21(4):991-1009, doi:10.1590/1516-731320150040013.

12. Neves PAPFG, Silva MDB, Vasconcelos SM, Silva SCJ, Hora NN. A experimentação como método inovador para o ensino de ciências: estudo realizado com uma turma do curso de pedagogia. Scientia Plena. 2016;12(06):2-9, doi:10.14808/sci.plena.2016.069906.

13. PISA. Programme International for Student Assessment 2016. Disponível em: www.oecd.org/pisa/. Acesso em: 22 de setembro de 2017.

14. CGEE. Centro de Gestão e Estudos Estratégicos. Percepção Pública da Ciência e Tecnologia 2015 Ciência e Tecnologia no Olhar dos Brasileiros. Brasília: Centro de Gestão e Estudos Estratégicos; 2015. $15 \mathrm{p}$

15. Alisson E. Conhecimento da Sociedade sobre Ciência na América Latina é Dramático. São Paulo: Agência Fapesp, 2015. Disponível em: http://agencia.fapesp.br/conhecimento_da_sociedade_sobre_ciencia_na_america_latina_e_dramatico/ 20985/. Acesso em: 06 de outubro de 2017.

16. Praia J, Gil-Pérez D, Vilches A. O papel da natureza da ciência na educação para a cidadania. Ciênc Educ. 2007;13(2):141-56, doi:10.1590/S1516-73132007000200001.

17. Robles SLR, Chávez MGG, Ballesteros AC. El campo de la salud ambiental: una oportunidad para alcanzar las metas de la educación científica. Amb Soc. 2015;18(4):75-96, doi:10.1590/18094422ASOC944V1842015.

18. Brandi ATE, Gurgel CMA. A alfabetização científica e o processo de ler e escrever em séries iniciais: emergências de um estudo de investigação-ação. Ciênc Educ. 2002;8(1):113-25, doi:10.1590/S151673132002000100009

19. Oliveira MA. Alfabetização científica no clube de ciências do ensino fundamental: uma questão de inscrição. Ens Pesq Educ Ciênc. 2010;12(2):11-26, doi:10.1590/1983-21172010120202.

20. Nigro RG, Azevedo MN. Ensino de ciências no fundamental I: perfil de um grupo de professores em formação continuada num contexto de alfabetização científica. Ciênc Educ. 2011;17(3):705-20, doi:10.1590/S1516-73132011000300012.

21. Brito LO, Fireman EC. Ensino de ciências por investigação: uma estratégia pedagógica para a promoção da alfabetização científica nos primeiros anos do ensino fundamental. Rev Ensaio Pesq Ciências. 2016;18(1):123-46, doi:10.1590/1983-21172016180107.

22. Costa LG, Costa APA. O ensino de física das radiações na formação de auxiliares de enfermagem e atendentes de consultórios odontológicos: sondagem de concepções sobre os raios-x com enfoque na prevenção e tecnologia. Ciênc Educ. 2002;8(2):161-5, doi:10.1590/S1516-73132002000200002.

23. Chassot A. Alfabetização científica: uma possibilidade para a inclusão social. Rev Bras Educ. 2003;22:89-100, doi:10.1590/S1413-24782003000100009.

24. Santos WLP. Educação científica na perspectiva de letramento como prática social: funções, princípios e desafios. Rev Bras Educ. 2007;12(36):474-492, doi:10.1590/S1413-24782007000300007.

25. Sasseron LH, Carvalho AMP. Construindo argumentação na sala de aula: a presença do ciclo argumentativo, os indicadores de alfabetização científica e o padrão de Toulmin. Ciênc Educ. 2011;17(10):97-114, doi:10.1590/S1516-73132011000100007.

26. Moreira LM. Oxigênio: uma abordagem filosófica visando discussões acerca da educação em ciências - parte 1: poder e ambição. Ciênc Educ. 2012;18(4):803-18, doi:10.1590/S1516-73132012000400005.

27. Souza VFM, Sasseron LH. As interações discursivas no ensino de física: a promoção da discussão pelo professor e a alfabetização científica dos alunos. Ciênc Educ. 2012;18(3):593-611, doi:10.1590/S151673132012000300007. 
28. Ramos LC, Sá LP. A alfabetização científica na educação de jovens e adultos em atividades baseadas no programa "mão na massa". Ens Pesq Educ Ciênc. 2013;15(2):123-40, doi:10.1590/198321172013150208.

29. Razera JCC, Souza CSS. O ensino informal de ciências no ambiente de postos de saúde: uma analogia com o ambiente museotécnico à luz da teoria sócio-histórica de Vygotski. Ens Pesq Educ Ciênc. 2013;15(1):31-48, doi:10.1590/1983-21172013150103

30. Teixeira FM. Alfabetização científica: questões para reflexão. Ciênc Educ. 2013;19(4):795-809, doi:10.1590/S1516-73132013000400002.

31. Moraes AC. Ciência e ideologia na prática dos professores de sociologia no ensino médio: da neutralidade impossível ao engajamento indesejável, ou seria o inverso? Educ Real. 2014;39(1):17-38, doi:10.1590/S2175-62362014000100003.

32. Moreira LM, Marandino M. Teatro de temática científica: conceituação, conflitos, papel pedagógico e contexto brasileiro. Ciênc Educ. 2015;21(2):511-23, doi:10.1590/1516-731320150020015.

33. Motokane MT. Sequências didáticas investigativas e argumentação no ensino de ecologia. Ens Pesq Educ Ciênc. 2015;17(spe):115-38, doi:10.1590/1983-2117201517s07.

34. Sasseron LH. Alfabetização científica, ensino por investigação e argumentação: relações entre ciências da natureza e escola. Ens Pesq Educ Ciênc. 2015;17(spe):49-67, doi:10.1590/1983-2117201517s04.

35. Rosa LMR, Suart RC, Marcondes MER. Regência e análise de uma sequência de aulas de química: contribuições para a formação inicial docente reflexiva. Ciênc Educ. 2017;23(1):51-70, doi 10.1590/1516-731320170010004.

36. Belintane C. Leitura e alfabetização no Brasil: uma busca para além da polarização. Educ Pesq. 2006;32(2):261-277, doi:10.1590/S1517-97022006000200004.

37. Vóvio CL, Kleiman AB. Letramento e alfabetização de pessoas jovens e adultas: um balanço da produção científica. Cad CEDES. 2013;33(90):177-96, doi:10.1590/S0101-32622013000200002.

38. Cunha RB. Alfabetização científica ou letramento científico? Interesses envolvidos nas interpretações da noção de scientific literacy. Rev Bras Educ. 2017;22(68):169-86, doi:10.1590/s141324782017226809.

39. Marques SRL, Lemos SM. A. Instrumentos de avaliação do letramento em saúde: revisão de literatura. Audiol Com Res. 2017;22: e1757, doi:10.1590/2317-6431-2016-1757.

40. Martins NFF, Abreu DPG, Silva BT, Semedo DSRC, Pelzer MT, Ienczak FS. Letramento funcional em saúde e adesão à medicação em idosos: revisão integrativa. Rev Bras Enf. 2017;70(4):868-874, doi:10.1590/0034-7167-2016-0625.

41. Silva WR. Formação sustentável do professor no mestrado profissional. Rev Bras Educ. 2017;22(70):708-31, doi:10.1590/s1413-24782017227036.

42. Cachapuz A, Gil-Perez D, Carvalho AMP, Vilches A. A necessária renovação do ensino das ciências. São Paulo: Cortez; 2005. 264p.

43. Brasil. Secretaria de Educação Básica. Parâmetros Curriculares Nacionais: Ciências Naturais. Brasília: MEC; 1997.

44. Brasil. Ministério da Educação. Base Nacional Comum Curricular- BNCC $2^{\mathrm{a}}$ versão. Brasília: Ministério da Educação; 2016. 472p.

45. Krasilchik M. Caminhos do ensino de ciências no Brasil. Em Aberto. 1992;11(55):4-8.

46. Grandelle R. Pesquisadores Criticam Ensino 'Decoreba' de Ciências nas Escolas do País. Jornal O Globo. 02 de Maio de 2016. Disponível em: <http://oglobo.globo.com/sociedade/ciencia/pesquisadores-criticam-ensino-decoreba-de-ciencias-nasescolas-do-pais-19208355>. Acesso em: 16 de Maio de 2016. 